\title{
Association between Body Mass Index and All-Cause Mortality in Hypertensive Adults: Results from the China Stroke Primary Prevention Trial (CSPPT)
}

\author{
Wei Yang ${ }^{1}$, Jian-Ping $\mathrm{Li}^{1}{ }^{1}$, Yan Zhang ${ }^{1}$, Fang-Fang Fan ${ }^{1}$, Xi-Ping $\mathrm{Xu}{ }^{2}$, Bin-Yan Wang ${ }^{2}, \mathrm{Xin}_{\mathrm{Xu}}{ }^{2}$, \\ Xian-Hui Qin ${ }^{2}$, Hou-Xun Xing ${ }^{3}$, Gen-Fu Tang ${ }^{3}$, Zi-Yi Zhou ${ }^{3}$, Dong-Feng Gu ${ }^{4}$, Dong Zhao 5 \\ and Yong Huo ${ }^{1, *}$ \\ 1 Department of Cardiology, Peking University First Hospital, Beijing 100034, China; \\ ywyy2008@163.com (W.Y.); lijianping@medmail.com.cn (J.-P.L.); drzhy1108@163.com (Y.Z.); \\ fang9020@126.com (F.-F.F.) \\ 2 National Clinical Research Center for Kidney Disease, State Key Laboratory for Organ Failure Research, \\ Renal Division, Nanfang Hospital, Southern Medical University, Guangzhou 510515, China; \\ xipingxu126@126.com (X.-P.X.); binyanwang126@126.com (B.-Y.W.); xux007@163.com (X.X.); \\ xianhuiqin@126.com (X.-H.Q.) \\ 3 Institute for Biomedicine, Anhui Medical University, Hefei 230032, China; ausachina@163.com (H.-X.X.); \\ tanggenfu@163.com (G.-F.T.); zhouziyi19920319@126.com (Z.-Y.Z.) \\ 4 State Key Laboratory of Cardiovascular Disease, Fuwai Hospital, National Center \\ for Cardiovascular Diseases, Chinese Academy of Medical Sciences and Peking Union Medical College, \\ Beijing 100037, China; gudongfeng@vip.sina.com \\ 5 Department of Epidemiology, Beijing Anzhen Hospital, Capital Medical University, \\ Beijing Institute of Heart, Lung and Blood Vessel Diseases, Beijing 100029, China; deezhao@vip.sina.com \\ * Correspondence: huoyong@263.net.cn; Tel.: +86-10-83572283
}

Received: 11 April 2016; Accepted: 15 June 2016; Published: 22 June 2016

\begin{abstract}
The association between elevated body mass index (BMI) and risk of death has been reported in many studies. However, the association between BMI and all-cause mortality for hypertensive Chinese adults remains unclear. We conducted a post-hoc analysis using data from the China Stroke Primary Prevention Trial (CSPPT). Cox regression analysis was performed to determine the significance of the association of BMI with all-cause mortality. During a mean follow-up duration of 4.5 years, 622 deaths (3.0\%) occurred among the 20,694 participants aged $45-75$ years. A reversed J-shaped relationship was observed between BMI and all-cause mortality. The hazard ratios (HRs) for underweight $\left(<18.5 \mathrm{~kg} / \mathrm{m}^{2}\right)$, overweight $\left(24.0-27.9 \mathrm{~kg} / \mathrm{m}^{2}\right)$, and obesity $\left(\geqslant 28.0 \mathrm{~kg} / \mathrm{m}^{2}\right)$ were calculated relative to normal weight $\left(18.5-23.9 \mathrm{~kg} / \mathrm{m}^{2}\right)$. The summary HRs were $1.56(95 \% \mathrm{CI}$, 1.11-2.18) for underweight, 0.78 (95\% CI 0.64-0.95) for overweight and 0.64 (95\% CI, $0.48-0.85$ ) for obesity. In sex-age-specific analyses, participants over 60 years of age had optimal BMI in the obesity classification and the results were consistent in both males and females. Relative to normal weight, underweight was associated with significantly higher mortality. Excessive weight was not associated with increased risk of mortality. Chinese hypertensive adults had the lowest mortality in grade 1 obesity.
\end{abstract}

Keywords: obesity; body mass index; mortality; hypertension; China

\section{Introduction}

Obesity is a global epidemic issue that is highly prevalent in both developed and developing countries; it affects people of both sexes and all ages, has adverse health consequences, accrues large economic costs, and has negative social implications [1]. Body mass index (BMI), defined as weight in kilograms divided by the square of the height in meters, is commonly used in clinical practice to screen 
for overweight and obesity and to guide weight loss recommendations. In China, an increasingly large proportion of the population has a BMI $\geqslant 25 \mathrm{~kg} / \mathrm{m}^{2}$, the standard definition of overweight [2]. Although obesity has been demonstrated to be associated with multiple non-communicable diseases, including hypertension, type 2 diabetes, coronary heart disease, stroke and several cancers [3], the association between BMI and all-cause mortality remains controversial: a direct association, a J-shaped, a U-shaped, or a reversed J-shaped relationship have all been recently reported [4-8].

The World Health Organization (WHO) defines the following six categories based on BMI values: $<18.5 \mathrm{~kg} / \mathrm{m}^{2}=$ underweight; 18.5 to $24.9 \mathrm{~kg} / \mathrm{m}^{2}=$ normal weight; 25.0 to $29.9 \mathrm{~kg} / \mathrm{m}^{2}$ = overweight; 30.0 to $34.9 \mathrm{~kg} / \mathrm{m}^{2}$ = grade 1 obesity; 35.0 to $39.9 \mathrm{~kg} / \mathrm{m}^{2}=$ grade 2 obesity; and $\geqslant 40 \mathrm{~kg} / \mathrm{m}^{2}=$ grade 3 obesity [9]. These definitions of overweight and obesity are mainly based on criteria derived from studies that involved populations of European origin. It has been suggested that the associations of BMI with body composition and health outcomes may differ between Asian and European populations [10]. The BMI cut-off points for overweight and obesity should be lower for Asian populations than they are for European populations (suggested cut-off points for Asians are $\geqslant 23.0 \mathrm{~kg} / \mathrm{m}^{2}$ for overweight and $\geqslant 27.5 \mathrm{~kg} / \mathrm{m}^{2}$ for obesity) [10]. However, a consensus statement from the WHO concluded that the available data were not sufficient to support Asian-specific cut-off points [10]. The Ministry of Health of the People's Republic of China determined a reclassification of BMI for Chinese adults that differs from the WHO classification: underweight $\left(<18.5 \mathrm{~kg} / \mathrm{m}^{2}\right)$, normal weight $\left(18.5-23.9 \mathrm{~kg} / \mathrm{m}^{2}\right)$, overweight $\left(24.0-27.9 \mathrm{~kg} / \mathrm{m}^{2}\right)$ and obesity $\left(\geqslant 28.0 \mathrm{~kg} / \mathrm{m}^{2}\right)[11]$.

For decades, the prevalence of hypertension has been increasing in China, and by the year 2010 it reached $20 \%$ [12]. During the period of 2005-2009, about $42 \%$ of Chinese adults aged 35-70 years were hypertensive [12]. Although obesity is clearly regarded as a risk factor for developing hypertension, the optimal BMI for middle-aged or elderly hypertensive Chinese remains unclear. Therefore, the objective of this study was to evaluate the relationship between BMI and all-cause mortality in hypertensive Chinese adults.

\section{Materials and Methods}

\subsection{Data Sources}

This post-hoc analysis utilizes data from the China Stroke Primary Prevention Trial (CSPPT), which enrolled 20,702 subjects with primary hypertension in a multi-community, randomized, double-blind, controlled trial to assess whether enalapril maleate and folic acid supplementation was more effective in reducing risk of stroke than enalapril maleate supplementation alone. This study was conducted in accordance with the principles of the Declaration of Helsinki. The Human Subjects Committee at the Biomedical Institute of Anhui Medical University approved the study protocol. All patients provided written informed consent prior to data collection.

\subsection{Participants and Treatment}

The methods and primary results of the CSPPT trial have been reported elsewhere [13]. Briefly, the CSPPT was conducted from 19 May 2008 to 24 August 2013 in 32 communities in Jiangsu and Anhui Provinces in China. Eligible participants were men and women aged 45-75 years old who had hypertension, defined as seated resting systolic blood pressure (SBP) $\geqslant 140 \mathrm{mmHg}$ or diastolic blood pressure (DBP) $\geqslant 90 \mathrm{mmHg}$ at both the screening and recruitment visit, or who were on anti-hypertensive medication. The major exclusion criteria included history of physician-diagnosed stroke, myocardial infarction (MI), heart failure, post-coronary revascularization, or congenital heart disease.

The current analysis was designed to investigate the relationship between BMI and all-cause mortality in this cohort. All-cause mortality included death due to any reason. After excluding eight subjects with missing information on weight and height, the final analysis included 20,694 subjects. Participants contributed person-years from the date of recruitment until date of death or end of 
follow-up (24 August 2013). BMI classifications as set according to the guidelines from the Ministry of Health of the People's Republic of China were used and included: underweight $\left(<18.5 \mathrm{~kg} / \mathrm{m}^{2}\right)$, normal weight $\left(18.5-23.9 \mathrm{~kg} / \mathrm{m}^{2}\right)$, overweight $\left(24.0-27.9 \mathrm{~kg} / \mathrm{m}^{2}\right)$ and obesity $\left(\geqslant 28.0 \mathrm{~kg} / \mathrm{m}^{2}\right)$. At the initial study visit trained research staff measured and recorded height (to the nearest $0.1 \mathrm{~cm}$ ) and weight (to the nearest $0.1 \mathrm{~kg}$ ) for each participant. In addition, trained staff collected baseline demographic data, medical history, and medication use. Cigarette smoking was classified into never, former, and current smoker (defined as smoke at least one cigarette per day for more than one year). Alcohol drinking was stratified into never, former and current drinker (defined as drink alcohol at least twice weekly for more than one year). Education was categorized into illiterate (0 years of education), primary school (1-6 years), and secondary school (>6 years) or above. Stress was defined as mild, moderate or severe according to the participant's personal evaluation.

\subsection{Follow-Up and Outcomes}

Patients were evaluated every three months for an average of five years to assess blood pressure (BP), adherence to medication, and adverse outcomes including stroke, composite major cardiovascular (CV) events and resultant death, and all-cause death. The study outcomes were adjudicated according to standard criteria by a clinical end points committee.

\subsection{Statistical Analysis}

All participants were divided into four groups according to the Chinese classification for BMI $\left(<18.5,18.5-23.9,24.0-27.9, \geqslant 28.0 \mathrm{~kg} / \mathrm{m}^{2}\right)$. Baseline characteristics of all participants were compared using the analysis of variance (ANOVA) for continuous variables and the $\chi^{2}$ test for categorical variables. All-cause mortality was first assessed using the Kalpan-Meier method and log-rank tests, and then multivariable Cox proportional-hazards regression models were applied to calculate hazard ratios (HR) and 95\% confidence intervals (CI) for the risk of all-cause mortality in each of the BMI groups. Potential confounders were adjusted including sex, age, center, baseline and on-treatment $\mathrm{BP}$, smoking status, alcohol drinking, education, stress, fasting blood glucose (FBG), total cholesterol (TC), triglycerides (TG), serum creatinine (SCr), homocysteine (Hcy) and albumin. Further stratified analyses by subgroups including sex, age, center, smoking and alcohol drinking status, education, stress and albumin levels were also explored by Cox proportional-hazards regression models to test for consistency of results. All tests were two-sided, and $p$-values less than 0.05 were considered statistically significant. All analyses were performed by EmpowerStats [14] and the statistical package R [15].

\section{Results}

\subsection{Patient Characteristics}

Baseline characteristics of all patients are presented in Table 1. Of the 20,694 participants, $59.0 \%$ were female, and the mean age was 60.0 years (SD, 7.5 years), with a range from 45 to 75 years. The mean BMI was $25.0 \mathrm{~kg} / \mathrm{m}^{2}\left(\mathrm{SD}, 3.4 \mathrm{~kg} / \mathrm{m}^{2}\right)$. Men had a lower of BMI $24.2 \mathrm{~kg} / \mathrm{m}^{2}\left(\mathrm{SD}, 3.7 \mathrm{~kg} / \mathrm{m}^{2}\right)$ than women, who had a BMI of $25.4 \mathrm{~kg} / \mathrm{m}^{2}\left(\mathrm{SD}, 3.4 \mathrm{~kg} / \mathrm{m}^{2}\right)$. The percentages of underweight, normal weight, overweight and obese were $2.5 \%, 39.1 \%, 38.9 \%$ and $19.5 \%$, respectively. Higher BMI categories were associated with younger age, female gender, better education, and higher levels of FBG, TC, TG, albumin, and baseline and on-treatment blood pressure measurements. Lower BMI categories were associated with higher HDL-C levels and current smoking status. 
Table 1. Baseline characteristics of the study participants by BMI categories ${ }^{1}$.

\begin{tabular}{|c|c|c|c|c|c|c|}
\hline \multirow{2}{*}{ Variables } & \multicolumn{6}{|c|}{ BMI Categories, $\mathrm{kg} / \mathrm{m}^{2}$} \\
\hline & All Subjects & $<18.5$ & $18.5-23.9$ & $24.0-27.9$ & $\geqslant 28.0$ & $p$-Value \\
\hline Number (\%) & 20,694 & $526(2.5)$ & $8083(39.1)$ & $8043(38.9)$ & $4042(19.5)$ & \\
\hline Age, mean (SD), years & $60.0(7.5)$ & $64.6(6.7)$ & $61.3(7.4)$ & $59.3(7.5)$ & $58.2(7.4)$ & $<0.001$ \\
\hline BMI, mean (SD), $\mathrm{kg} / \mathrm{m}^{2}$ & $25.0(3.7)$ & $17.5(0.8)$ & $21.8(1.4)$ & $25.8(1.1)$ & $30.4(2.2)$ & $<0.001$ \\
\hline Male, No. (\%) & $8491(41.0)$ & $271(51.5)$ & $3863(47.8)$ & $3137(39.0)$ & $1220(30.2)$ & $<0.001$ \\
\hline Center, No. (\%) & & & & & & $<0.001$ \\
\hline Anqing & $5211(25.2)$ & $350(66.5)$ & 3119 (38.6) & $1406(17.5)$ & $336(8.3)$ & \\
\hline Lianyungang & $15,483(74.8)$ & 176 (33.5) & 4964 (61.4) & $6637(82.5)$ & 3706 (91.7) & \\
\hline \multicolumn{7}{|l|}{$\mathrm{SBP}$, mean (SD), mmHg } \\
\hline baseline & $166.9(20.4)$ & $164.3(17.9)$ & $166.0(20.0)$ & $167.1(20.4)$ & $168.4(21.4)$ & $<0.001$ \\
\hline on-treatment & $139.4(10.9)$ & $138.8(10.8)$ & $138.9(11.0)$ & $139.4(10.8)$ & $140.4(11.0)$ & $<0.001$ \\
\hline \multicolumn{7}{|l|}{$\mathrm{DBP}$, mean $(\mathrm{SD}), \mathrm{mmHg}$} \\
\hline baseline & $94.1(11.9)$ & $88.0(11.4)$ & $91.8(11.7)$ & $95.0(11.6)$ & $97.7(11.9)$ & $<0.001$ \\
\hline on-treatment & $82.9(7.5)$ & $78.9(7.7)$ & $81.5(7.4)$ & $83.5(7.2)$ & $85.3(7.2)$ & $<0.001$ \\
\hline Pulse, mean (SD),bpm & $73.6(10.1)$ & $74.0(11.0)$ & $73.6(10.2)$ & $73.5(10.1)$ & $73.8(9.9)$ & 0.53 \\
\hline Smoking status (\%) & & & & & & $<0.001$ \\
\hline never & $14,252(68.9)$ & $293(55.7)$ & $5015(62.1)$ & $5791(72.0)$ & $3153(78.0)$ & \\
\hline former & $1567(7.6)$ & $35(6.7)$ & $604(7.5)$ & 649 (8.1) & $279(6.9)$ & \\
\hline current & $4867(23.5)$ & $198(37.6)$ & $2459(30.4)$ & $1601(19.9)$ & $609(15.1)$ & \\
\hline Alcohol drinking (\%) & & & & & & $<0.001$ \\
\hline never & $14,265(69.0)$ & $343(65.2)$ & $5155(63.8)$ & $5665(70.5)$ & $3102(76.8)$ & \\
\hline former & $1458(7.0)$ & $52(9.9)$ & $609(7.5)$ & $540(6.7)$ & $257(6.4)$ & \\
\hline current & $4960(24.0)$ & $131(24.9)$ & $2313(28.6)$ & $1836(22.8)$ & $680(16.8)$ & \\
\hline Education $(\%)$ & & & & & & $<0.001$ \\
\hline illiterate & $13,221(63.9)$ & $365(69.4)$ & $5261(65.1)$ & 4999 (62.2) & $2596(64.3)$ & \\
\hline primary & $3446(16.7)$ & $103(19.6)$ & $1468(18.2)$ & $1296(16.1)$ & $579(14.3)$ & \\
\hline secondary or above & 4015 (19.4) & $58(11.0)$ & $1347(16.7)$ & $1745(21.7)$ & $865(21.4)$ & \\
\hline Stress $(\%)$ & & & & & & 0.035 \\
\hline mild & $12,578(60.8)$ & $289(54.90)$ & $4846(60.0)$ & $4960(61.7)$ & $2479(61.4)$ & \\
\hline moderate & $6921(33.4)$ & $204(38.8)$ & $2765(34.2)$ & $2627(32.7)$ & $1323(32.8)$ & \\
\hline severe & $1189(5.7)$ & $33(6.3)$ & $464(5.7)$ & $454(5.6)$ & $237(5.9)$ & \\
\hline FPG, mean (SD), $\mathrm{mmol} / \mathrm{L}$ & $5.8(1.7)$ & $5.3(1.6)$ & $5.6(1.6)$ & $5.9(1.8)$ & $6.1(1.7)$ & $<0.001$ \\
\hline $\mathrm{TC}$, mean $(\mathrm{SD}), \mathrm{mmol} / \mathrm{L}$ & $5.5(1.2)$ & $5.0(1.2)$ & $5.4(1.2)$ & $5.6(1.2)$ & $5.7(1.2)$ & $<0.001$ \\
\hline $\mathrm{TG}$, mean (SD), mmol/L & $1.7(1.2)$ & $1.2(0.5)$ & $1.4(0.8)$ & $1.8(1.0)$ & $2.0(1.8)$ & $<0.001$ \\
\hline HDL-C, mean (SD), $\mathrm{mmol} / \mathrm{L}$ & $1.3(0.4)$ & $1.6(0.4)$ & $1.5(0.4)$ & $1.3(0.3)$ & $1.2(0.3)$ & $<0.001$ \\
\hline $\mathrm{SCr}$, mean (SD), umol/L & $66.0(19.3)$ & $67.6(16.7)$ & $67.3(19.6)$ & $65.6(20.5)$ & $64.0(16.3)$ & $<0.001$ \\
\hline Hcy, mean (SD), umol/L & $14.5(8.4)$ & $14.3(7.7)$ & $14.5(8.1)$ & $14.5(8.4)$ & $14.3(8.9)$ & 0.534 \\
\hline Albumin, mean (SD), g/L & $49.0(5.9)$ & $47.57(6.6)$ & $48.57(6.0)$ & $49.34(5.7)$ & $49.34(5.6)$ & $<0.001$ \\
\hline Treatment (\%) & & & & & & 0.832 \\
\hline Enalapril & $10,352(50.0)$ & $271(51.5)$ & 4053 (50.1) & $4025(50.0)$ & $2003(49.6)$ & \\
\hline Enalapril-Folic Acid & $10,342(50.0)$ & 255 (48.5) & 4030 (49.9) & $4018(50.0)$ & $2039(50.4)$ & \\
\hline
\end{tabular}

${ }^{1}$ For the determination of $p$-values, two-sample $t$-tests for continuous variables, chi-square tests for categorical variables. SBP, systolic blood pressure; DBP, diastolic blood pressure; FBG, fasting blood glucose; TC, total cholesterol; TG, triglycerides; SCr, serum creatinine; Hcy, homocysteine.

\subsection{BMI and Mortality}

The relationship between BMI and overall mortality for all patients with hypertension is shown in Table 2. During a median follow-up period of 4.5 years (88,466.64 person-years), 622 deaths occurred. Specifically, with increasing BMI, the all-cause mortality rate in underweight, normal weight, overweight and obese groups was 7.8\%, 3.9\%, 2.4\% and 1.8\%, respectively. According to the BMI category, the all-cause mortality rate per 1000 person-years was $17.63,8.93,5.76$ and 4.24, respectively. In a crude Cox proportional-hazards regression model, the HRs were 1.97 (95\% CI, 1.42-2.73) for underweight, 0.64 (95\% CI, 0.54-0.77) for overweight and 0.47 (95\% CI, 0.37-0.61) for obesity compared with normal weight. In model II, after adjusting for sex, age, center, baseline and on-treatment BP, smoking status, alcohol drinking, education, stress and serum biochemical measurements, the HRs were 1.56 (95\% CI, 1.11-2.18) for underweight, 0.78 (95\% CI, 0.64-0.95) for overweight and 0.64 (95\% CI, 0.48-0.85) for obesity compared with normal weight. 
Table 2. Hazard ratios for all-cause mortality according to BMI status ${ }^{1}$.

\begin{tabular}{cccccccc}
\hline \multirow{2}{*}{ BMI kg/m $\mathbf{m}^{2}$} & \multirow{2}{*}{$\boldsymbol{N}$} & \multirow{2}{*}{ Event (\%) } & \multirow{2}{*}{ Curde Rate } & \multicolumn{4}{c}{ All-Cause Mortality } \\
\cline { 5 - 8 } & & & & Model 1 & $p$-Value & Model 2 & $p$-Value \\
\hline Continuous & 20,694 & $622(3.0 \%)$ & 7.03 & $0.90(0.88,0.92)$ & $<0.001$ & $0.94(0.91,0.96)$ & $<0.001$ \\
$<18.5$ & 526 & $41(7.8 \%)$ & 17.63 & $1.97(1.42,2.73)$ & $<0.001$ & $1.56(1.11,2.18)$ & 0.010 \\
$18.5-23.9$ & 8083 & $312(3.9 \%)$ & 8.93 & 1 & & 1 & \\
$24.0-27.9$ & 8043 & $197(2.4 \%)$ & 5.76 & $0.64(0.54,0.77)$ & $<0.001$ & $0.78(0.64,0.95)$ & 0.012 \\
$\geqslant 28$ & 4042 & $72(1.8 \%)$ & 4.24 & $0.47(0.37,0.61)$ & $<0.001$ & $0.64(0.48,0.85)$ & 0.002 \\
\hline
\end{tabular}

${ }^{1}$ Multivariable Cox proportional-hazards regression models were applied to calculate hazard ratios (HR) and $95 \%$ confidence intervals (CI) for the risk of all-cause mortality in each of the BMI groups. A BMI $\left(\mathrm{kg} / \mathrm{m}^{2}\right)$ of 18.5-23.9 was used as the reference to estimate all HRs. Crude rates are all-cause mortality per 1000 person-years. Model 1: crude; Model 2: adjustment for sex, age, center, baseline and on-treatment BP, smoking status, alcohol drinking, education, stress, fasting blood glucose, total cholesterol, triglycerides, serum creatinine, homocysteine, albumin.

Figure 1 shows the Kaplan-Meier curves of the cumulative hazards of all-cause mortality stratified by BMI categories. All-cause mortality between each of the four BMI groups was significantly different (log-rank test, $p<0.001$ ). With increased BMI, the cumulative mortality risk gradually decreased, rendering the underweight group with the maximum mortality risk.

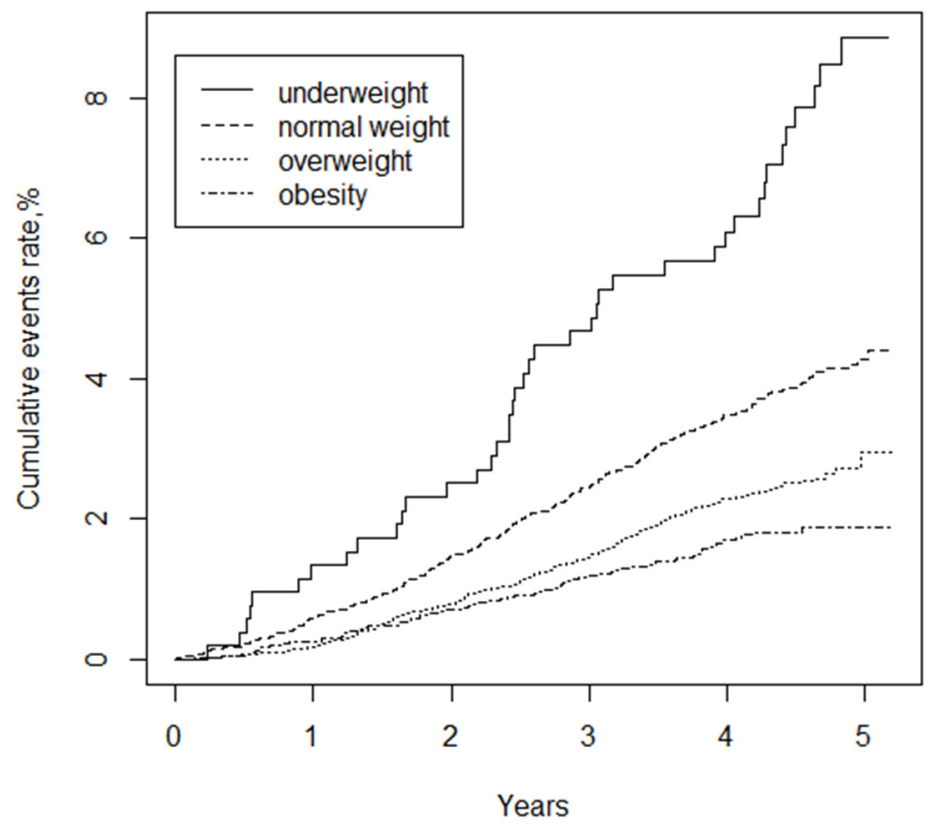

Figure 1. Kaplan-Meier curves of cumulative hazards of all-cause mortality stratified by BMI categories (underweight $<18.5$, normal weight $18.5-23.9$, overweight $24.0-27.9$, obesity $\geqslant 28.0 \mathrm{~kg} / \mathrm{m}^{2}$ ). log-rank test, $p<0.001$.

Further stratified analyses were performed by important covariables including gender, center, smoking status, alcohol drinking status, education, stress and albumin levels (Table 3). There were no significant interactions in any of the subgroups ( $p>0.05$ for all comparisons). The beneficial effect appeared to be more pronounced in participants older than 60 years.

We subsequently repeated the analysis using narrower BMI categories $(<18.5,18.5-19.9,20.0-21.9$, $\left.22.0-23.9,24.0-25.9,26.0-27.9,28.0-29.9,30-34.9, \geqslant 35 \mathrm{~kg} / \mathrm{m}^{2}\right)$ to delineate the relationship between BMI and mortality with greater precision. Compared to patients with normal BMI (between 22.0 and $\left.23.9 \mathrm{~kg} / \mathrm{m}^{2}\right)$, patients with grade 1 obesity $\left(30-34.9 \mathrm{~kg} / \mathrm{m}^{2}\right)$ had the lowest risk of all-cause mortality (Figure 2). However, all-cause mortality increased drastically for patients with severe obesity $\left(\geqslant 35 \mathrm{~kg} / \mathrm{m}^{2}\right)$. 
Table 3. Multivariable hazard ratios for mortality ${ }^{1}$.

\begin{tabular}{|c|c|c|c|c|c|c|c|c|c|c|c|}
\hline \multirow{3}{*}{ Variables } & \multirow{3}{*}{$N$} & \multirow{3}{*}{ Death, $n$} & \multirow{3}{*}{$\%$} & \multicolumn{7}{|c|}{ BMI Categories $\left(\mathrm{kg} / \mathrm{m}^{2}\right)$} & \multirow{3}{*}{ Adjusted ${ }^{*} p$ for Interaction } \\
\hline & & & & \multicolumn{2}{|c|}{$<18.5$} & \multirow{2}{*}{$\begin{array}{c}18.5-23.9 \\
\text { HR } 95 \% \text { CI }\end{array}$} & \multicolumn{2}{|c|}{$24.0-27.9$} & \multicolumn{2}{|c|}{$\geqslant 28$} & \\
\hline & & & & HR 95\%CI & $p$-Value & & HR 95\%CI & $p$-Value & HR 95\%CI & $p$-Value & \\
\hline All Participants & 20,694 & 622 & 3.0 & $1.56(1.10,2.14)$ & 0.012 & 1 & $0.80(0.66,0.97)$ & 0.026 & $0.66(0.49,0.87)$ & 0.003 & \\
\hline Sex & & & & & & & & & & & 0.692 \\
\hline Females & 12,203 & 258 & 2.1 & $1.24(0.66,2.33)$ & 0.505 & 1 & $0.78(0.58,1.05)$ & 0.097 & $0.60(0.41,0.89)$ & 0.010 & \\
\hline Males & 8491 & 364 & 4.3 & $1.74(1.16,2.58)$ & 0.007 & 1 & $0.82(0.63,1.07)$ & 0.144 & $0.71(0.46,1.09)$ & 0.119 & \\
\hline Center & & & & & & & & & & & 0.719 \\
\hline Anqing & 5211 & 218 & 4.2 & $1.58(1.04,2.38)$ & 0.030 & 1 & $0.72(0.49,1.05)$ & 0.090 & $0.88(0.45,1.72)$ & 0.709 & \\
\hline Lianyungang & 15,483 & 404 & 2.6 & $1.59(0.88,2.88)$ & 0.125 & 1 & $0.84(0.67,1.06)$ & 0.153 & $0.65(0.47,0.90)$ & 0.009 & \\
\hline Age & & & & & & & & & & & 0.588 \\
\hline$<60$ & 10,469 & 172 & 1.6 & $1.82(0.78,4.25)$ & 0.167 & 1 & $0.82(0.56,1.19)$ & 0.302 & $0.84(0.52,1.34)$ & 0.463 & \\
\hline$\geqslant 60$ & 10,225 & 450 & 4.4 & $1.62(1.13,2.34)$ & 0.009 & 1 & $0.75(0.60,0.95)$ & 0.016 & $0.53(0.36,0.76)$ & $<0.001$ & \\
\hline Smoking Status & & & & & & & & & & & 0.298 \\
\hline Never & 14,254 & 327 & 2.3 & $1.40(0.83,2.37)$ & 0.208 & 1 & $0.80(0.61,1.04)$ & 0.090 & $0.62(0.43,0.89)$ & 0.009 & \\
\hline Former & 1570 & 75 & 4.8 & $3.76(1.64,8.67)$ & 0.002 & 1 & $1.37(0.75,2.49)$ & 0.305 & $1.28(0.56,2.90)$ & 0.558 & \\
\hline Current & 4869 & 219 & 4.5 & $1.33(0.79,2.25)$ & 0.281 & 1 & $0.70(0.50,1.00)$ & 0.052 & $0.60(0.33,1.09)$ & 0.095 & \\
\hline \multicolumn{12}{|l|}{ Alcohol } \\
\hline Never & 14,265 & 355 & 2.5 & $1.54(0.98,2.43)$ & 0.064 & 1 & $0.75(0.58,0.97)$ & 0.026 & $0.63(0.44,0.89)$ & 0.009 & 0.906 \\
\hline Former & 1458 & 80 & 5.5 & $2.51(1.17,5.42)$ & 0.019 & 1 & $0.85(0.48,1.48)$ & 0.559 & $0.50(0.20,1.28)$ & 0.148 & \\
\hline Current & 4960 & 186 & 3.8 & $1.27(0.65,2.47)$ & 0.482 & 1 & $0.93(0.65,1.34)$ & 0.695 & $0.84(0.46,1.55)$ & 0.581 & \\
\hline Education & & & & & & & & & & & 0.599 \\
\hline Illiterate & 13,221 & 411 & 3.1 & $1.43(0.95,2.15)$ & 0.087 & 1 & $0.75(0.59,0.96)$ & 0.021 & $0.67(0.48,0.94)$ & 0.022 & \\
\hline Primary & 3446 & 116 & 3.3 & $1.52(0.70,3.31)$ & 0.290 & 1 & $0.98(0.63,1.53)$ & 0.935 & $0.49(0.22,1.09)$ & 0.080 & \\
\hline Secondary or above & 4015 & 94 & 2.3 & $2.18(0.88,5.40)$ & 0.093 & 1 & $0.78(0.47,1.29)$ & 0.330 & $0.68(0.33,1.39)$ & 0.290 & \\
\hline Stress & & & & & & & & & & & 0.506 \\
\hline Mild & 12,574 & 391 & 3.1 & $1.26(0.79,2.00)$ & 0.333 & 1 & $0.73(0.57,0.94)$ & 0.013 & $0.66(0.47,0.94)$ & 0.019 & \\
\hline Moderate & 6919 & 202 & 2.9 & $1.89(1.13,3.17)$ & 0.016 & 1 & $0.91(0.64,1.29)$ & 0.602 & $0.58(0.33,1.01)$ & 0.054 & \\
\hline Severe & 1188 & 28 & 2.4 & $\begin{array}{c}2.97(0.59 \\
14.93)\end{array}$ & 0.187 & 1 & $1.29(0.49,3.42)$ & 0.604 & $0.90(0.24,3.32)$ & 0.869 & \\
\hline Albumin, $g / L$ & & & & & & & & & & & 0.527 \\
\hline$<49$ & 11,813 & 412 & 3.5 & $1.48(1.00,2.18)$ & 0.051 & 1 & $0.73(0.57,0.93)$ & 0.012 & $0.68(0.48,0.97)$ & 0.033 & \\
\hline$\geqslant 49$ & 8876 & 210 & 2.4 & $1.87(0.98,3.56)$ & 0.058 & 1 & $0.87(0.63,1.20)$ & 0.394 & $0.56(0.34,0.90)$ & 0.016 & \\
\hline
\end{tabular}

${ }^{1}$ Cox proportional-hazards regression models to test interaction terms between BMI and other factors, but none were found to be significant. * Adjustment for sex, age, center, baseline and on-treatment BP, smoking status, alcohol drinking, education, stress, fasting blood glucose, total cholesterol, triglycerides, serum creatinine, homocysteine, albumin; sex, center, age, smoking status, alcohol, education, stress and albumin were not adjusted for in each corresponding subgroup analyses. 


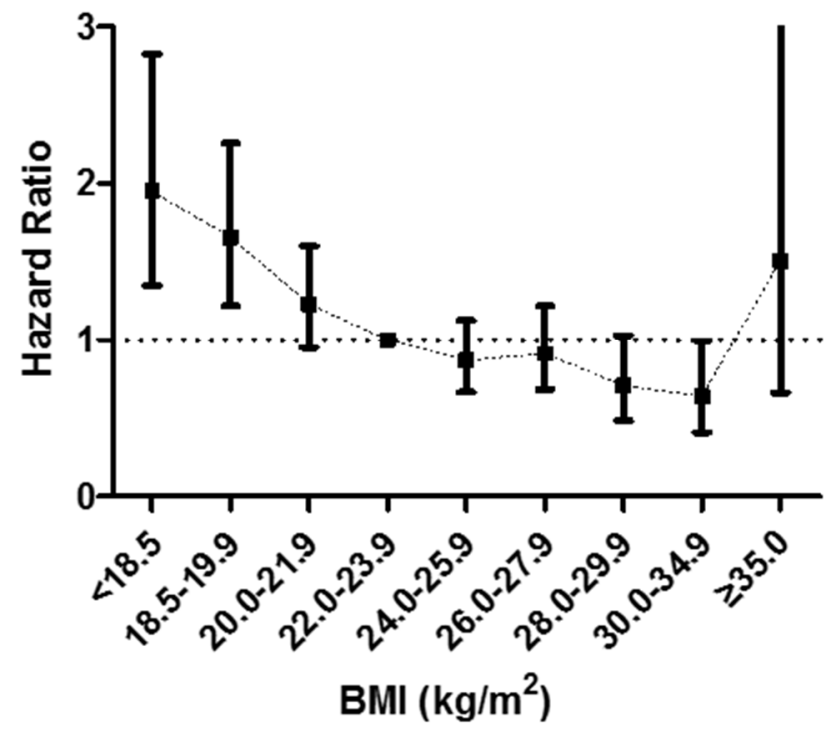

Figure 2. Hazard ratios for all-cause mortality according to narrower BMI categories. A BMI (in $\mathrm{kg} / \mathrm{m}^{2}$ ) of 22.0-23.9 was used as the reference to estimate all HRs. Adjustment for sex, age, center, baseline and on-treatment BP, smoking status, alcohol drinking, education, stress, fasting blood glucose, total cholesterol, triglycerides, serum creatinine, homocysteine, albumin.

\section{Discussion}

Our post-hoc analysis of this Chinese population with primary hypertension in the CSPPT showed the association between BMI and all-cause mortality followed a reversed J-shaped curve with increased risk at low and high BMI status. Even after adjusting for potential confounders, the results were similar. Compared to normal weight, the HRs were 1.56 (95\% CI, 1.11-2.18) for underweight, 0.78 (95\% CI, 0.64-0.95) for overweight and $0.64(95 \%$ CI, $0.48,0.85)$ for obesity. In this population, the optimal BMI was grade 1 obesity $\left(30-34.9 \mathrm{~kg} / \mathrm{m}^{2}\right)$. Stratified analyses were consistent in all important covariables. Moreover, overweight or obese patients older than 60 years showed the most benefit.

Many studies conducted on different populations showed a U-shaped or J-shaped association between BMI and all-cause mortality, which is consistent with our results when applied to the underweight participants only [4-8]. In these studies, the population age distribution and whether subgroup analyses were performed by age group might be two major reasons for the controversial results. Janssen et al. found that BMI was inversely associated with mortality risk in elderly Asians [16]. Compared to middle-aged adults, some previous studies found that the optimal BMI among the elderly shifted upwards $[17,18]$. This finding is similar to what has been observed in other Asian regions such as Taiwan [19], Hong Kong [20], India and Bangladesh [8], among others [4,5,7]. Many of the elderly participants from these studies were residents of live-in care facilities, and/or were diagnosed with a health ailment such as hypertension, or were from undeveloped communities compared with urban residents. However, the optimal range of BMI proposed among the elderly varies among studies. As the world's population ages and the number of hypertensive adults rises, our findings are important for health care professionals and policy-makers whose decisions affect elderly hypertensives.

Several potential explanations for the observed obesity paradox seen in our study exist. Firstly, reverse causality is a major problem in observational studies. For example, weight loss is classically experienced prior to death among the elderly who are ill. Secondly, socioeconomic status could confound the association between BMI and the risk of death, as people from less well-developed countries with a high BMI are more likely to have a higher socioeconomic status, allowing them better access to health care than those with a lower BMI [8]. However, the participants in our study are from rural communities, and a similar relation between BMI and socioeconomic status exists for them. Thirdly, in a meta-analysis of patients with existing coronary artery disease, those classified as 
overweight and obese had longer survival rates, potentially because of the benefit from the body's reservation of nutrition within the population of elderly suffering from illness [21]. Fourthly, intensive pharmacotherapy could play a large role in the reverse J-shaped relationship. It has been demonstrated that patients with intensive pharmacotherapy are more likely to reach targets for secondary prevention. In population studies conducted in the USA and Canada, obese patients are more likely to meet targets for BP, lipids, and glycemic control than normal-weight patients [22]. In addition, hypertensive participants are relatively less healthy compared to the general population, although in our study we excluded patients with stroke and MI. Mary et al. found that among elderly Chinese with poor health status, there was an inverse, dose-response relationship between BMI and mortality, and this relationship was more pronounced in the group with the most morbidity compared to subjects of normal weight [23]. Another interpretation is that BMI can be a marker of adiposity, fitness and muscle mass, so that BMI maintenance in older people serves as an overall marker of health. Song et al. accessed the sex-age-specific association between BMI and all-cause mortality in the general population, and showed that the optimal BMI increased according to age and the trend was consistent in both males and females [24]. Similarly, Woo et al. found that in older elderly (aged over 75 years), a higher BMI was a protection from mortality [17].

Our study also has several limitations. Firstly, our participants were all middle-aged or elderly hypertensives; therefore, the result of this study cannot be generalized to all populations. Secondly, with the strict exclusion of the history of cardiovascular disease, cardiovascular cause of death counted for only $14 \%$ of all-cause death, which is less than other studies conducted on Chinese hypertensive adults. The association between BMI and a specific cause of death cannot be analyzed. Thirdly, in the current study, relatively few elderly were $\geqslant 30 \mathrm{~kg} / \mathrm{m}^{2}(10 \%$ of total subjects) and $\geqslant 35 \mathrm{~kg} / \mathrm{m}^{2}(1 \%)$; thus, the impact of obesity cannot be adequately assessed. Moreover, although we have excluded subjects with a baseline diagnosis of coronary heart disease, stroke, cancer, or acquired organic diseases, some preexisting illness may modify the association between BMI and mortality risk. However, according to our investigation, after excluding those subjects with no history of disease at baseline and who survived the first two years of follow-up, the BMI and all-cause mortality association was consistent with all 4.5 years of this study.

\section{Conclusions}

In conclusion, this study revealed a reversed J-shaped association between BMI and all-cause mortality in Chinese hypertensive adults. Relative to normal weight, underweight was associated with significantly higher mortality. Excessive weight was not associated with increased risk of mortality. A BMI classification of grade 1 obesity for Chinese hypertensive adults without stroke or MI showed the lowest mortality. Additional large-scale prospective studies with well-controlled confounding factors are needed to further address this important public health issue.

Acknowledgments: This research was supported by the Ministry of Science and Technology of the People's Republic of China (2012zx 09101105); the Major State Basic Research Development Program of China (973 program, No. 2012CB517703); and Projects of National Natural Science Foundation of China (grants 81437052).

Author Contributions: Y.H.: study supervision, access to all data in the study, integrity of data, and accuracy of the data analysis; W.Y., F.F.F., X.P.X., Z.Y.Z. and Y.H.: study concept and design and statistical analysis; X.P.X., B.Y.W., X.X., X.H.Q., H.X.X., G.F.T. and Y.H.: acquisition of data; W.Y., F.F.F., X.P.X., B.Y.W., Z.Y.Z. and Y.H.: analysis and interpretation of data; W.Y. and Y.H.: drafting of the manuscript; X.P.X., D.F.G. and D.Z. provided a critical review of the content of the manuscript, and revised the manuscript for important intellectual content; J.P.L., Y.Z., X.P.X., B.Y.W., H.X.X., G.F.T. and Y.H.: administrative, technical, or material support; and all authors: critical revision of the manuscript for important intellectual content.

Conflicts of Interest: The authors declare no conflict of interest.

\section{Abbreviations}

The following abbreviations are used in this manuscript: 


$\begin{array}{ll}\text { BMI } & \text { body mass index } \\ \text { BP } & \text { blood pressure } \\ \text { CI } & \text { confidence interval } \\ \text { CSPPT } & \text { China Stroke Primary Prevention Trial } \\ \text { CV } & \text { major cardiovascular } \\ \text { DBP } & \text { diastolic blood pressure } \\ \text { FBG } & \text { fasting blood glucose } \\ \text { Hcy } & \text { homocysteine } \\ \text { HR } & \text { hazard ratio } \\ \text { MI } & \text { myocardial infarction } \\ \text { SBP } & \text { systolic blood pressure } \\ \text { SCr } & \text { serum creatinine } \\ \text { TC } & \text { total cholesterol } \\ \text { TG } & \text { triglycerides } \\ \text { WHO } & \text { The World Health Organization }\end{array}$

\section{References}

1. Yang, Z.; Hall, A.G. The Financial Burden of Overweight and Obesity among Elderly Americans: The Dynamics of Weight, Longevity, and Health Care Cost. Health Serv. Res. 2008, 43, 849-868. [CrossRef] [PubMed]

2. World Health Organization. WHO Global Infobase, 2014. Available online: http://www.who.int/gho/ncd/ risk_factors/overweight_text/en/ (accessed on 22 December 2015).

3. World Health Organization. Physical Status: The Use and Interpretation of Anthropometry; Report of a WHO Expert Committee; WHO Technical Report Series No. 854; World Health Organization: Geneva, Switzerland, 1995.

4. Flegal, K.M.; Graubard, B.I.; Williamson, D.F.; Gail, M.H. Excess deaths associated with underweight, overweight, and obesity. JAMA 2005, 293, 1861-1867. [CrossRef] [PubMed]

5. Flegal, K.M.; Kit, B.K.; Orpana, H.; Graubard, B.I. Association of all-cause mortality with overweight and obesity using standard body mass index categories: A systematic review and meta-analysis. JAMA 2013, 309, 71-82. [CrossRef] [PubMed]

6. Hu, F.B.; Willett, W.C.; Li, T.; Stampfer, M.J.; Colditz, G.A.; Manson, J.E. Adiposity as Compared with Physical Activity in Predicting Mortality among Women. N. Engl. J. Med. 2004, 351, 2694-2703. [CrossRef] [PubMed]

7. Winter, J.E.; MacInnis, R.J.; Wattanapenpaiboon, N.; Nowson, C.A. BMI and all-cause mortality in older adults: A meta-analysis. Am. J. Clin. Nutr. 2014, 99, 875-890. [CrossRef] [PubMed]

8. Zheng, W.; McLerran, D.F.; Rolland, B.; Zhang, X.; Inoue, M.; Matsuo, K.; He, J.; Gupta, P.C.; Ramadas, K.; Tsugane, S.; et al. Association between body-mass index and risk of death in more than 1 million Asians. N. Engl. J. Med. 2011, 364, 719-729. [CrossRef] [PubMed]

9. Haslam, D.W.; James, W.P. Obesity. Lancet 2005, 366, 1197-1209. [CrossRef]

10. WHO Expert Consultation. Appropriate body-mass index for Asian populations and its implications for policy and intervention strategies. Lancet 2004, 363, 157-163.

11. Chen, C.; Lu, F.C. The guidelines for prevention and control of overweight and obesity in Chinese adults. Biomed. Environ. Sci. 2004, 17, 1-36. [PubMed]

12. Liu, L.S. 2010 Chinese guidelines for the management of hypertension. Zhonghua Xin Xue Guan Bing Za Zhi 2011, 39, 579-615. [PubMed]

13. Huo, Y.; Li, J.; Qin, X.; Huang, Y.; Wang, X.; Gottesman, R.F.; Tang, G.; Wang, B.; Chen, D.; He, M.; et al. Efficacy of Folic Acid Therapy in Primary Prevention of Stroke Among Adults With Hypertension in China. JAMA 2015, 313, 1325. [CrossRef] [PubMed]

14. EmpowerStats. Available online: http://www.empowerstats.com (accessed on 25 March 2016).

15. R Software, Verson 3.2.1. Available online: http://www.R-project.org/ (accessed on 25 March 2016).

16. Janssen, I.; Mark, A.E. Elevated body mass index and mortality risk in the elderly. Obes. Rev. 2007, 8, 41-59. [CrossRef] [PubMed]

17. Woo, J.; Ho, S.C.; Sham, A. Longitudinal changes in body mass index and body composition over 3 years and relationship to health outcomes in Hong Kong Chinese age 70 and older. J. Am. Geriatr. Soc. 2001, 49, 737-746. [CrossRef] [PubMed] 
18. Chung, W.; Ho, F.; Cheng, N.; Lee, M.; Yeh, C. BMI and all-cause mortality among middle-aged and older adults in Taiwan: A population-based cohort study. Public Health. Nutr. 2015, 18, 1839-1846. [CrossRef] [PubMed]

19. Lin, W.; Albu, J.; Liu, C.; Huang, H.; Pi-Sunyer, F.X.; Li, C.; Li, T.; Lin, C.; Huang, K. Larger Body Mass Index and Waist Circumference Are Associated with Lower Mortality in Chinese Long-Term Care Facility Residents. J. Am. Geriatr. Soc. 2010, 58, 2092-2098. [CrossRef] [PubMed]

20. Lee, J.S.W.; Auyeung, T.; Chau, P.P.H.; Hui, E.; Chan, F.; Chi, I.; Woo, J. Obesity Can Benefit Survival-A 9-Year Prospective Study in 1614 Chinese Nursing Home Residents. J. Am. Med. Dir. Assoc. 2014, 15, 342-348. [CrossRef] [PubMed]

21. Romero-Corral, A.; Montori, V.M.; Somers, V.K.; Korinek, J.; Thomas, R.J.; Allison, T.G.; Mookadam, F.; Lopez-Jimenez, F. Association of bodyweight with total mortality and with cardiovascular events in coronary artery disease: A systematic review of cohort studies. Lancet 2006, 368, 666-678. [CrossRef]

22. Chang, V.W.; Asch, D.A.; Werner, R.M. Quality of care among obese patients. JAMA 2010, 303, $1274-1281$. [CrossRef] [PubMed]

23. Schooling, C.M.; Lam, T.H.; Li, Z.B.; Ho, S.Y.; Chan, W.M.; Ho, K.S.; Tham, M.K.; Cowling, B.J.; Leung, G.M. Obesity, physical activity, and mortality in a prospective Chinese elderly cohort. Arch. Intern. Med. 2006, 166, 1498-1504. [CrossRef] [PubMed]

24. Yi, S.; Ohrr, H.; Shin, S.; Yi, J. Sex-age-specific association of body mass index with all-cause mortality among 12.8 million Korean adults: A prospective cohort study. Int. J. Epidemiol. 2015, 44, 1696-1705. [CrossRef] [PubMed]

(c) 2016 by the authors; licensee MDPI, Basel, Switzerland. This article is an open access article distributed under the terms and conditions of the Creative Commons Attribution (CC-BY) license (http:/ / creativecommons.org/licenses/by/4.0/). 